\title{
GCU
}

Glasgow Caledonian

University

University for the Common Good

\section{Reaction kinetics and oxidation product formation in the degradation of acetaminophen by ferrate (VI)}

Wang, Hongyu; Liu, Yibing; Jiang, Jia-Qian

Published in:

Chemosphere

DOI:

10.1016/j.chemosphere.2016.04.088

Publication date:

2016

Document Version

Author accepted manuscript

Link to publication in ResearchOnline

Citation for published version (Harvard):

Wang, H, Liu, Y \& Jiang, J-Q 2016, 'Reaction kinetics and oxidation product formation in the degradation of acetaminophen by ferrate (VI)', Chemosphere, vol. 155, pp. 583-590.

https://doi.org/10.1016/j.chemosphere.2016.04.088

\section{General rights}

Copyright and moral rights for the publications made accessible in the public portal are retained by the authors and/or other copyright owners and it is a condition of accessing publications that users recognise and abide by the legal requirements associated with these rights.

Take down policy

If you believe that this document breaches copyright please view our takedown policy at https://edshare.gcu.ac.uk/id/eprint/5179 for details

of how to contact us. 
1 Reaction kinetics and oxidation product formation in the degradation of

2 acetaminophen by ferrate (VI)

3 Hongyu Wang ${ }^{1, *}$, Yibing Liu ${ }^{1}$, Jia-Qian Jiang ${ }^{2, *}$

$4{ }^{1}$ School of Civil Engineering and Architecture, Zhejiang University of Technology,

$5 \quad$ Hangzhou 310014, People's Republic of China

$6{ }^{2}$ School of Engineering and Built Environment, Glasgow Caledonian University,

7 Glasgow G4 0BA, Scotland, United Kingdom

8

9

10

11

12

13

14

15

16

*Corresponding authors:

17

Hongyu Wang, Tel.: +86 5718887 1516; Fax: (+86) 571-88320180.

18 E-mail address: hywang@zjut.edu.cn

19 Jia-Qian Jiang, Tel.: +44(0) 1413318850

20

E-mail address: jiaqian.jiang@gcu.ac.uk

21 


\section{Abstract}

This paper investigates the degradation of acetaminophen (AAP) in aqueous solutions by ferrate (VI), aiming to propose the kinetics, pathways and the oxidation products' formation in the AAP degradation. A series of jar tests were undertaken over ferrate (VI) dosages (molar ratios of ferrate (VI):AAP, 5:1 to 25:1) and $\mathrm{pH}$ values (4 11). The effects of co-existing ions $(0.2 \sim 5 \mathrm{mM})$ and humic acid $\left(10 \sim 50 \mathrm{mg} \cdot \mathrm{l}^{-1}\right)$ on the AAP removal were investigated. Ferrate (VI) can remove 99.6 \% AAP (from 1000 $\left.\mu \mathrm{g} \cdot 1^{-1}\right)$ in 60 minutes under study conditions when majority of the AAP reduction occurred in the first 5 minutes. The treatment performance depended on the ferrate(VI) dosage, $\mathrm{pH}$ and the type and strength of co-existing ions and humic acid. Raising ferrate (VI) dosage with optimal pH 7 improved the AAP degradation. In the presence of humic acid, the AAP degradation by ferrate (VI) was promoted in a short period $(<30 \mathrm{~min})$ but then inhibited with increasing in humic acid contents. The presence of $\mathrm{Al}^{3+}, \mathrm{CO}_{3}{ }^{2-}$ and $\mathrm{PO}_{4}{ }^{3-}$ ions declined but the existence of $\mathrm{K}^{+}, \mathrm{Na}^{+}, \mathrm{Mg}^{2+}$ and $\mathrm{Ca}^{2+}$ ions can improve the AAP removal. The catalytic function of $\mathrm{Al}^{3+}$ on the decomposition of ferrate (VI) in aqueous solution was found.

The kinetics of the reaction between ferrate (VI) and AAP was pseudo first-order for ferrete (VI) and pseudo second-order for AAP. The pseudo rate constant of ferrate (VI) with AAP was $1.4 \times 10^{-5} \mathrm{~L}^{2} \cdot \mathrm{mg}^{-2} \cdot \mathrm{min}^{-1}$. Three oxidation products (OPs) were identified and the AAP degradation pathways were proposed.

Keywords: Potassium ferrate (VI); Acetaminophen; Reaction mechanism; Influence factors; Oxidation products 


\section{Introduction}

In recent years, pharmaceutical and personal care products (PPCPs) have been detected in numerous water resources (Boyd et al., 2003; Kim et al., 2009; Liu and Wong, 2013). The potential hazard toward aquatic organisms and public health (Fent et al., 2006; Crane et al., 2006; Witorsch and Thomas, 2010) resulting from increasing PPCPs concentrations, and the incomplete removal of PPCPs has been found in various conventional wastewater treatment plants (Boyd et al., 2003; Khetan and Collins, 2007). As a typical anti-inflammatory and analgesic medication, acetaminophen (AAP) is produced and consumed about $1.45 \times 10^{5}$ tons per year worldwide (Kasprzyk-Horderna et al., 2008). AAP has high solubility up to 12.78 $\mathrm{g} \cdot \mathrm{kg}^{-1}$ in aqueous solutions at $20^{\circ} \mathrm{C}$, and has been detected frequently in water courses (Granberg and Rasmuson, 1999). More than $65 \mu \mathrm{g} / \mathrm{L}$ of acetaminophen has been detected in surface water and the concentration of acetaminophen might be much higher in pharmaceutical industry wastewater (Roberts and Thomas, 2006). Research has shown that AAP had toxicity on bivalve Dreissena polymorpha (Parolini et al., 2013).

Due to the possession of dual functions of oxidation and coagulation, ferrate (VI) has been studied widely and demonstrated to be a very promising chemical for both water and waste water treatment (Jiang and Lloyd, 2002; Lee et al., 2004; Jiang et al., 2006). The elimination of PPCPs by ferrate (VI) has been conducted by many researchers (e.g., Yang et al., 2012; Jiang et al., 2013; Jiang, 2014; Sharma et al., 2015). So far, the degradation of AAP has been reported by anodic oxidation with a 
boron-doped diamond electrode (Brillas et al., 2005), subsurface flow constructed wetlands (Ranieri et al., 2011), ozonation and $\mathrm{H}_{2} \mathrm{O}_{2} / \mathrm{UV}$ system (Andreozzi et al., 2003), Photo-Fenton process (Trovo et al., 2008) and $\mathrm{TiO}_{2}$ photocatalysis (Yang et al., 2008). However, to the best of our knowledge, the study on the degradation of AAP using ferrate (VI) has not been reported so far.

And thus, this study focused on the removal of AAP in aqueous solutions by ferrate (VI). Conditions of the degradation of AAP were investigated with respect to ferrate (VI) dosage, $\mathrm{pH}$ value, and the presence of humic acid and various co-existing ions $\left(\mathrm{K}^{+}, \mathrm{Na}^{+}, \mathrm{Mg}^{2+}, \mathrm{Ca}^{2+}, \mathrm{Al}^{3+}, \mathrm{CO}_{3}{ }^{2-}, \mathrm{SO}_{4}{ }^{2-}, \mathrm{PO}_{4}{ }^{3-}\right)$. The study also aimed to reveal oxidation products (OPs) and kinetics for the degradation of AAP by ferrate (VI).

\section{Experimental section}

\subsection{Chemicals and reagents}

Acetaminophen (AAP) was purchased from aladdin (Shanghai, China); Sodium hydroxide, methanol (LC) and potassium hydroxide (AR) were purchased from Hangzhou Xiaoshan Chemical Reagent Factory (Hangzhou, China); Humic acid (HA) was obtained from Nanjing Chemical Reagent Factory (Nanjing, China). Ferrate (VI) solution of high concentration was synthesized by the electro-chemical way (Wang et al., 2015), and then transferred to solid potassium ferrate (VI) after various purification steps (Li et al., 2005). The ferrate(VI) strength of the resulting dry product was measured by chromite method and direct spectrophotometric method 
using a wavelength of $505 \mathrm{~nm}$ and an absorbance coefficient of $1100 \mathrm{M}^{-1} \cdot \mathrm{cm}^{-1}$ (Jiang et al., 2009). The purity of ferrate (VI) was continuously monitored on the daily basis. The other reagents were supplied by Sinopharm Chemical Reagent Co. Ltd. (Shanghai, China). Experimental water was generated by ultra pure water supplier (UPHW1-90T, Sichuan europtronic ultra pure Technology Co. Ltd., China). Stock solutions of AAP were prepared in pure water at $100 \mathrm{mg} \cdot \mathrm{l}^{-1}$ for the use of jar test experiments, identification of oxidation products and kinetic analysis.

\subsection{Jar test experiment}

The oxidation of AAP by ferrate (VI) was studied using a magnetic stirrer (Color squid, IKA (Guangzhou) equipment Co. Ltd, China) with a mixing speed of $600 \mathrm{rpm}$. Pipette (Shanghai Kangmin inspection equipment Co. Ltd, China) was used for sampling at given reaction time intervals; 1, 2, 5, 10, 20, 40 and 60 min, respectively, and sodium hyposulfite was used as a quencher.

In order to examine the formation of AAP oxidation product as well as to assess the degradation performance readily, two initial AAP concentrations, 500 and 1000 $\mu \mathrm{g} \cdot \mathrm{l}^{-1}$ respectively, were used for the study. The selected AAP concentrations were also in line with that used by other researchers (e.g., Yang et al., 2008). The influence of operating conditions were investigated using $100 \mathrm{~mL}$ test solutions with initial AAP concentrations of $1000 \mu \mathrm{g} \cdot \mathrm{l}^{-1}$ and by adjusting a number of ferrate (VI) dosages, $\mathrm{pH}$ values and HA concentrations. Ferrate (VI) was dosed into the test solution as dried powder and the dosage applied was in the molar ratio of ferrate (VI):AAP from 5:1 to 25:1. The $\mathrm{pH}$ of test solutions was adjusted by $0.01 \mathrm{M}$ hydrochloric acid and $0.01 \mathrm{M}$ 

$111 \mathrm{mg} \cdot \mathrm{l}^{-1}$

sodium hydroxide to $\mathrm{pH} 4 \sim 11$. The HA concentration in testing solutions was $10 \sim 50$

Test solutions of $200 \mathrm{~mL}$ with AAP initial concentration of $500 \mu \mathrm{g} \cdot 1^{-1}$ were used to study the impact of the presence of $0.2 \sim 5 \mathrm{mM}$ co-existing ions $\left(\mathrm{K}^{+}, \mathrm{Na}^{+}, \mathrm{Mg}^{2+}\right.$, $\mathrm{Ca}^{2+}, \mathrm{Al}^{3+}, \mathrm{CO}_{3}{ }^{2-}, \mathrm{SO}_{4}{ }^{2-}, \mathrm{PO}_{4}{ }^{3-}$ ) on the AAP degradation performance by ferrate(VI). The AAP solutions were mixed with given amount of $\mathrm{NaCl}, \mathrm{KCl}, \mathrm{MgCl}_{2}, \mathrm{CaCl}_{2}$, $\mathrm{Al}_{2}\left(\mathrm{SO}_{4}\right)_{3}, \mathrm{Na}_{2} \mathrm{CO}_{3}, \mathrm{Na}_{2} \mathrm{SO}_{4}$ and $\mathrm{Na}_{3} \mathrm{PO}_{4}$, respectively, to achieve the required ion concentrations. The ferrate (VI) with dosage of the molar ratio of 28:1(ferrate (VI):AAP) was mixed with the test solution and the sampling time was $0,1,2,3,5,7$ and $15 \mathrm{~min}$. All samples in jar test experiments were filtered by $0.45 \mu \mathrm{m}$ glass membrane filters (Shanghai Xingya purifying material factory, China) before analyzing the residual AAP concentrations. The AAP concentration and removal percentage of each sample were detected by liquid chromatography (LC) (see subsection 2.5).

\subsection{Identification of degradation products}

Test solutions of $1000 \mu \mathrm{g} \cdot 1^{-1}$ AAP were prepared in pure water. Ferrate (VI) was added to the solution of AAP with the molar ratio of 40:1. The samples were obtained after determined intervals, 0, 1, 5, 15, 30, 45 and $60 \mathrm{~min}$. Detailed procedures of identification of AAP degradation products can be seen in sub-section 2.5.

\subsection{Kinetic analysis}

Kinetic analysis of AAP with ferrate (VI) was performed at room temperature 
$131\left(20 \pm 2^{0} \mathrm{C}\right)$ under pseudo-first-order conditions with ferrate (VI) in excess. The test

132 solutions of AAP were prepared in pure water. A given ferrate (VI) dose of $32.5 \mathrm{mg} \cdot \mathrm{l}^{-}$

$133{ }^{1}$ was added into test solutions with AAP concentrations of $300,500,700,900 \mu \mathrm{g} \cdot 1^{-1}$

134 respectively. On the other hand, several ferrate (VI) doses, 13, 19.5, 26, $32.5 \mathrm{mg} \cdot \mathrm{l}^{-1}$

135 respectively, were dosed into the test solutions with a given AAP concentration of

$1361000 \mu \mathrm{g} \cdot \mathrm{l}^{-1}$. For the given time intervals as stated above, the reacting solutions were

137 quenched with sodium hyposulfite solution.

\subsection{Analytical methods}

The concentration of chemical oxygen demand (COD) of test solutions before and after ferrate (VI) treatment was measured by potassium dichromate method

141 (APHA et al., 1998). (IonPac AS19, $4 \times 250 \mathrm{~mm}$ ) and a flow rate of $0.8 \mathrm{~mL} \cdot \mathrm{min}^{-1}$ of $20 \mathrm{mM} \mathrm{KOH}$ solution, was used for the measurement of inorganic ions' concentrations.

The measurement of AAP was conducted by an Agilent 1200 LC system (Agilent, US) with diode array detector (DAD). The column utilised for the separation of compounds was a $5 \mu \mathrm{m}, 4.6 \times 150 \mathrm{~mm}$ reversed phase Eclipse XDB-C18 column (Agilent, US). The column was kept at $30{ }^{\circ} \mathrm{C}$ and eluted by $15 \%$ methanol and $85 \%$ pure water at a flow rate of $0.8 \mathrm{~mL} \cdot \mathrm{min}^{-1}$. The injection volume was $10 \mu 1$ and the DAD detection wavelength for AAP was $257 \mathrm{~nm}$.

The oxidation products of AAP treated by ferrate (VI) were analyzed by a GC- 
For each GC-MS injection, samples were pretreated by hydrochloric acid of $1 \mathrm{M}$ to $\mathrm{pH}<1$ and then extracted with chloroform (10 times concentrated). The GC conditions were given as follows: a sample volume of $1 \mu \mathrm{l}$ injected in the splitless mode at 280

${ }^{0} \mathrm{C}$ and the oven temperature programmed from $50{ }^{\circ} \mathrm{C}(5 \mathrm{~min})$ to $250{ }^{0} \mathrm{C}$ at $10{ }^{0} \mathrm{C} \mathrm{min}^{-1}$ followed by a 5 min hold at $250{ }^{\circ} \mathrm{C}$, and helium used as the carrier gas at a flow rate of $0.8 \mathrm{ml} \mathrm{min}{ }^{-1}$. Mass spectrometer was operated under electron ionization mode at 70 $\mathrm{eV}$ with mass scan range of 40 500.

\section{Results and discussion}

\subsection{Effect of reaction time and ferrate (VI) dosage}

Fig. 1. Effect of reaction time and ferrate (VI) dosage on AAP degradation

Fig. 1 shows the variation of AAP degradation efficiency vs. reaction time and ferrate (VI) dosages. The removal of AAP by ferrate (VI) mainly occurred within the first 5 min reactions, followed by a more gradual further removal over the next $10 \sim$ $55 \mathrm{~min}$. Increasing in the ferrate (VI) dose (as molar ratio of ferrate (VI): AAP) from 5:1 to 25:1, the removal efficiency of AAP increased sharply for the given time of 60 min; that the AAP removal percentage was $50.5,76.7,96.9$ and $99.6 \%$ for the molar ratio of $5: 1,10: 1,15: 1$ and $25: 1$, respectively. On the other hand, for a $10 \mathrm{~min}$ reaction and high ferrate(VI) dose (molar ratio of 25:1), approximate 90\% AAP was removed. In general, ferrate (VI) could remove AAP readily under these conditions. 

$\mathrm{mg}^{-1}$ and after ferrate(VI) treatment (ferrate (VI) dose of $0.325 \mathrm{~g} / \mathrm{L}$ ) the COD was reduced to $24 \mathrm{mg} \mathrm{l}^{-1}$ which gives $23 \%$ COD reduction, representing the optimal COD reduction performance. reaction time. It can be observed that for a given ferrate(VI) dose (25:1 as molar ratio, ferrate (VI):AAP) and $\mathrm{pH} 4$, AAP removal was about $85 \%$ and irrelevant to the reaction time. For other $\mathrm{pHs}$, AAP removal was less than $70 \%$ and $\mathrm{pH} 11$ was not favorable to the APP removal especially for short reaction time; only $11.3 \%$ AAP was approached to slight variations after $10 \mathrm{~min}$.

Fig. 2. Effect of different $\mathrm{pH}$ values on AAP degradation 
that at $\mathrm{pH} 11$, since ferrate (VI) possesses higher redox potential (2.2 ev) under acidic conditions than that for alkaline conditions. Moreover, ferrate (VI) has been reported to be dissociated to form different species in terms of solution $\mathrm{pH}$ as shown in equations 1-3 (Sharma, 2002) and in Fig. S1 of the supplementary material.

$$
\begin{aligned}
& \mathrm{H}_{3} \mathrm{FeO}_{4}^{+} \longleftrightarrow \mathrm{H}^{+}+\mathrm{H}_{2} \mathrm{FeO}_{4}, \mathrm{PK}_{\mathrm{a}}=1.6 \pm 0.2 \\
& \mathrm{H}_{2} \mathrm{FeO}_{4} \longleftrightarrow \mathrm{H}^{+}+\mathrm{HFeO}_{4}^{-}, \mathrm{PK}_{\mathrm{a}}=3.5 \\
& \mathrm{HFeO}_{4}^{-} \longleftrightarrow \mathrm{H}^{+}+\mathrm{FeO}_{4}{ }^{2-}, \mathrm{PK}_{\mathrm{a}}=7.3 \pm 0.1
\end{aligned}
$$

$$
\text { which are readily self-decomposed, resulting in rapid oxidation of APP which has }
$$
been demonstrated in Fig. 2 where the AAP removal was about $85 \%$ and irrelevant to the reaction time. Relatively for $\mathrm{pH} 7$, ferrate (VI) was stable and still had high oxidizing ability and then the best AAP removal performance was achieved for a long reaction duration $(60 \mathrm{~min})$.

The second effect of $\mathrm{pH}$ on the AAP degradation is attributed to the dissociating products of AAP. The $\mathrm{PK}_{\mathrm{a}}$ of AAP was 9.5, and dissociating and/or protonated species could be dominant when $\mathrm{pH}$ was 9 (see equation 4). Fig. 2 shows that for $\mathrm{pH} 9$, the AAP removal efficiency was high and it was close to that at $\mathrm{pH} 7$. Hence, the results observed from this study demonstrated that high protonated AAP species were readily degraded by ferrate (VI), which is consistent with that from the reported work where solutions containing phenol and chlorinated phenols were treated by ozone and ferrate 


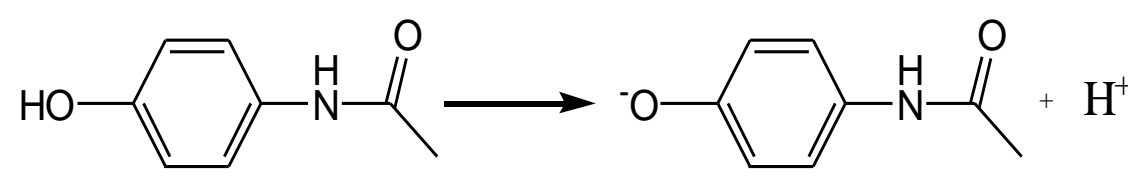

\subsection{Kinetics}

$$
\mathrm{r}=-\mathrm{d}[\mathrm{AAP}] \cdot \mathrm{d}_{\mathrm{T}}^{-1}=-\mathrm{k} \cdot[\operatorname{Ferrate}(\mathrm{VI})]^{\mathrm{a}} \cdot[\mathrm{AAP}]^{\mathrm{b}}
$$

where $r$ represents the reaction rate of ferrate (VI) with AAP, $k$ represents the overall

230 Where

$\mathrm{k}_{1}=\mathrm{k} \cdot[\text { Ferrate }(\mathrm{VI})]^{\mathrm{a}}$

Eq. (6) can be rewritten as

234 Eq. (7) can be rewritten as

237 Table1. Kinetic parameters of AAP degradation by ferrate (VI) 
Table 1 shows the initial concentrations of AAP, ferrate (VI) dosage, fitting

240 equations and initial reaction rate of AAP. It can be seen that the plot of the reciprocal of AAP concentrations versus reaction time were linear with good coefficient of correlation $\left(\mathrm{R}^{2}>0.90\right)$ at various concentrations of ferrate $(\mathrm{VI})$, indicating the reaction was second-order with respect to ferrate (VI). Moreover, the plot of the natural logarithm of AAP concentrations versus reaction time were linear with good correlation coefficient $\left(\mathrm{R}^{2}>0.90\right)$ at various concentrations of AAP, indicating the reaction was first-order with respect to AAP. Although ferrate (VI) was unstable, ferrate (VI) was always in excess in comparison to AAP within the studied reaction time. The value $a$ could be obtained as the slope of $\ln r$ versus $\ln [\mathrm{AAP}]$ with linear fitting and the $b$ is to be determined as the slope of $\ln \mathrm{k}_{1}$ versus $\ln [$ Ferrat(VI)] with linear fitting, and this can be seen in Figure 3. Thus, the values of $a$ and $b$ are 1.2

$251 \quad\left(\mathrm{R}^{2}=0.999\right)$ and $0.38\left(\mathrm{R}^{2}=0.939\right)$, respectively. The apparent third-order rate constant

252 (k) for the reaction was calculated through the intercept in vertical axis. The value of ferrate (VI) and AAP as

$$
r=-d[A A P] d_{T}^{-1}=-0.000014 \cdot[F \operatorname{errate}(V I)]^{1.20} \cdot[A A P]^{0.38}
$$

Fig. 3. Kinetic analysis of AAP degradation by ferrate (VI) 
Based on the measured m/z values and prior literature (Andreozzi et al., 2003;

261 Yang et al., 2009; Moctezuma et al., 2012), the best-fit chemical structures of

262 oxidation products (OPs) were tentatively proposed by considering the molecule

263 pattern of target compounds and the mechanism of ferrate (VI) oxidation; and the

264 probable structures of OPs (AAP-1-3)are presented in Fig. 4. AAP would be attacked

265 by ferrate (VI) which leads to the cleavage of imino group and the transformation of

266 acetyl amino group, forming AAP-1 and AAP-2 respectively. The formation of AAP-3

267 might attribute to further oxidation of intermediate OPs by ferrate (VI). Besides, the

$268 \mathrm{NO}_{3}{ }^{-}$was detected in the reaction solution which is consistent with previous studies

269 (Skoumal et al., 2006; Yang et al., 2009), and suggests that the possibility of the

270 broken of C-N bonds.

Fig. 4. Detection of oxidation products $(a-c)$ and original compound, AAP (d)

Fig. 5. Evolution of OPs and nitrate with decreasing of AAP concentration

Fig. 5 shows the evolution of OPs and nitrate during the AAP degradation by

ferrate (VI). As it can be observed, AAP-1-2 were formed from the first $1 \mathrm{~min}$

reaction, but almost disappeared, together with the AAP, after 60 min reactions. AAP-

2783 was detected after $15 \mathrm{~min}$ and trace nitrate $\left(\mathrm{C}_{\max }=0.038 \mathrm{mg} \mathrm{l}^{-1}\right)$ was detected in the

OPs by ferrate(VI) occurred.

Fig. 6 shows probable pathways of AAP degradation during the treatment by 
ferrate (VI). The oxidation product, AAP-1, was formed with loss of a $\mathrm{C}_{2} \mathrm{H}_{4} \mathrm{NO}$ group from the benzene ring, and the pathway was different with the formation of hydroquinone (Skoumal et al., 2006; Tao et al., 2015) in other AAP degradation. AAP-2 was generated by replacing the hydroxyl group with a quinonyl group and the further loss of a $\mathrm{C}_{2} \mathrm{H}_{3} \mathrm{O}$ group from the imino group. In accordance with previous literature ( Skoumal et al., 2006; Yang et al., 2008; Moctezuma et al., 2012), AAP-3 was also detected, which was a further oxidation product from AAP-1 (phenol). Reference to the prior knowledge (Santos, et al., 2002; Andreozzi et al., 2003; Wang et al., 2014), phenol would be oxidized into para-benzoquinone, which was then converted into maleic acid (AAP-3). The further degradation of AAP-3 could produce oxalic acid and formic acid (Santos, et al., 2002; Skoumal, et al., 2006). Besides, the formation of $\mathrm{NO}_{3}{ }^{-}$is due to the deamination of AAP and AAP-2. The attack by ferrate(VI) on the hydroxyl and acetamido groups is consistent with the conclusions made by Zhou and Jiang (2015), that electron-rich moieties were prone to react with ferrate (VI).

Fig. 6. Possible pathways of AAP degradation by ferrate (VI)

\subsection{The presence of humic acid}

Fig. 7. Effect of different HA dosage on AAP degradation 
ferrate (VI) treatment was investigated. Fig. 7 shows the changes in residual

concentrations of AAP corresponding to HA doses and for the reaction time. As it can

be observed, the removal of AAP increased during the intervals between 2 and $10 \mathrm{~min}$

efficiency of AAP with HA was less than that of AAP without HA. This suggests that

the presence of HA could accelerate the reaction rate of ferrate (VI) and AAP. The capacity (Sharma, 2010) and then assists to the removal of AAP. With increasing in the strength of HA, the removal efficiency of AAP first increased and then decreased, of PAA for the reaction time of 30 and $60 \mathrm{~min}$.

\subsection{Effect of coexisting ions}

$$
\mathrm{K}^{+}, \mathrm{Na}^{+}, \mathrm{Mg}^{2+}, \mathrm{Ca}^{2+}, \mathrm{CO}_{3}{ }^{2-}, \mathrm{SO}_{4}{ }^{2-} \text { and } \mathrm{PO}_{4}{ }^{3-} \text { ions are common ions in natural }
$$

water. Aluminum based coagulant is also widely used in water treatment. The effects

of above five cations and three anions on the removal percentage of AAP were

studied. In the presence of $\mathrm{K}^{+}, \mathrm{Na}^{+}, \mathrm{Mg}^{2+}, \mathrm{Ca}^{2+}, \mathrm{Al}^{3+}, \mathrm{CO}_{3}{ }^{2-}, \mathrm{SO}_{4}{ }^{2-}, \mathrm{PO}_{4}{ }^{3-}$ ions, the AAP removal efficiencies vs. reaction time are shown in Fig. 8(a) for the ion concentrations of $0.2 \mathrm{mM}$, in Fig. 8 (c) for $1 \mathrm{mM}$ and Fig. $8(\mathrm{e})$ for $5 \mathrm{mM}$, respectively. 
As it can be seen, $\mathrm{K}^{+}, \mathrm{Na}^{+}, \mathrm{Mg}^{2+}, \mathrm{Ca}^{2+}$ and $\mathrm{SO}_{4}{ }^{2-}$ ions can enhance the AAP removal, however, $\mathrm{Al}^{3+}, \mathrm{CO}_{3}{ }^{2-}$ and $\mathrm{PO}_{4}{ }^{3-}$ ions had the opposite effect. The higher the concentration of $\mathrm{Mg}^{2+}$, the greater the removal rate of AAP. The performance of $\mathrm{K}^{+}$, $\mathrm{Na}^{+}, \mathrm{Ca}^{2+}$ and $\mathrm{SO}_{4}{ }^{2-}$ mainly remained constant with the increasing concentration from 0.2 to $5 \mathrm{mM}$.

Table 2. Kinetic parameters of the AAP degradation in the presence of eight coexisting ions

Fig. 8(b), Fig. 8(d) and Fig. 8(f) show the linear fitting curve of the reciprocal of ferrate (VI) concentration and reaction time in the presence of the above ions. Table 2 shows the pseudo reaction rate constant $\left(\mathrm{K}_{\mathrm{obs}}\right)$ and correlation coefficient of the linear fitting curves for Fig. 8(b), Fig. 8(d) and Fig. 8(f). The good correlation coefficients $\left(\mathrm{R}^{2}>0.90\right.$, except $\left.\mathrm{Al}^{3+}\right)$ indicate that the reactions were pseudo second-order with respect to ferrate (VI), which is consistent with that shown in the previous section.

When raising the ions' concentration from 0.2 to $5 \mathrm{mM}$, the $\mathrm{K}_{\mathrm{obs}}$ of $\mathrm{CO}_{3}{ }^{2-}$ and $\mathrm{PO}_{4}{ }^{3-}$ ions decreased, from $4 \times 10^{-4}$ to $6.8 \times 10^{-5} \mathrm{~min}^{-1}$ and $5 \times 10^{-4}$ to $2.2 \times 10^{-5} \mathrm{~min}^{-1}$, respectively, but the $\mathrm{K}_{\mathrm{obs}}$ of $\mathrm{Mg}^{2+}$ increased, from $3.8 \times 10^{-3}$ to $8.4 \times 10^{-3} \mathrm{~min}^{-1}$. The resulting rate constants are theoretically evident to the observed effect of co-existing ions on the AAP removal by ferrate(VI); that $\mathrm{CO}_{3}{ }^{2-}$ and $\mathrm{PO}_{4}{ }^{3-}$ ions inhabited while $\mathrm{Mg}^{2+}$ ions were beneficial to the reaction between AAP and ferrate(VI). In the presence of metal cations, deprotonation of acid-base functional groups in AAP molecules can be accelerated due to the metal-AAP binding and this might also 
reduce the AAP $\mathrm{pK}_{\mathrm{a}}$ value (Jeffrey et al., 2006). In this work, the addition of $\mathrm{K}^{+}, \mathrm{Na}^{+}$, $\mathrm{Mg}^{2+}, \mathrm{Ca}^{2+}$ could enhance the deprotonation of AAP and then to accelerate the removal rate. Besides, hydrogen ion could be generated through the hydrolysis reaction of magnesium ion in aqueous solution. The accumulation of hydrogen ions helped the increase of oxidation potential of ferrate (VI) (Jiang, 2014). It may be the reason that the addition of $\mathrm{Mg}^{2+}$ has a greater removal rate of AAP than $\mathrm{Ca}^{2+}$.

In the presence of $\mathrm{Al}^{3+}, \mathrm{CO}_{3}{ }^{2-}$ and $\mathrm{PO}_{4}{ }^{3-}$ ions and when the concentration of each ion increased from 0.2 to $5 \mathrm{mM}$, the removal of AAP decreased from 66.7 to $22.4 \%$ for $\mathrm{Al}^{3+}, 74.2$ to $36.5 \%$ for $\mathrm{CO}_{3}{ }^{2-}$, and 79.9 to $13.1 \%$ for $\mathrm{PO}_{4}{ }^{3-}$, respectively. The hydrolysis of $\mathrm{CO}_{3}{ }^{2-}$ and $\mathrm{PO}_{4}{ }^{3-}$ in the aqueous solution could raise the alkalinity and then decreases the oxidation potential of ferrate (VI) and causes the reduction of AAP removal efficiency. This phenomenon was even clearly to observe when concentrations of phosphate and carbonate ions were greater.

\section{Table 3. Effect of aluminum ions on ferrate (VI) concentration}

In this work, the decomposition of ferrate (VI) caused by aluminium ions was found (Table 3). As can be seen when $500 \mu 1$ of aluminium ions solution was added, the ferrate (VI) concentration decreased by $79 \%$. This might be related to the hydrolysis of $\mathrm{Al}^{3+}$ to produce hydrogen ions into solution, (Eq. 11), which then accelerates the decomposition of ferrate (VI) and could lower the AAP removal efficiency. 


$$
\mathrm{Al}^{3+}+3 \mathrm{H}_{2} \mathrm{O}=\mathrm{Al}(\mathrm{OH})_{3}+3 \mathrm{H}^{+}
$$

Fig. 8. Effect of different ions on AAP degradation

\section{Conclusions}

The treatment of AAP in aqueous solutions by ferrate (VI) was investigated.

Results demonstrated that AAP can be removed effectively under the experimental

better performance on the AAP degradation. Besides, the pseudo rate constant of was proposed to be the main pathway of the AAP degradation scheme. Moreover, in the presence of HA, a short time interval $(<30 \mathrm{~min})$ would favour to but longer reaction time (30-60 min) decreased the degradation of AAP. The presence of $\mathrm{K}^{+}$, $\mathrm{Na}^{+}, \mathrm{Mg}^{2+}$ and $\mathrm{Ca}^{2+}$ ions in aqueous solutions can improve the AAP removal efficiency by ferrate(VI), and the most promoting effect of $\mathrm{Mg}^{2+}$ was observed. The presence of $\mathrm{Al}^{3+}, \mathrm{CO}_{3}{ }^{2-}$ and $\mathrm{PO}_{4}{ }^{3-}$ would decline the AAP degradation performance significantly. The catalytic function of $\mathrm{Al}^{3+}$ to the ferrate (VI) decomposition in the AAP reduction by ferrate (VI). 

wish to appreciate the assistance received from the staff of Biological and Environmental Engineering College at Zhejiang University of Technology for the sample analysis by mass spectroscopy.

\section{Supplementary material}

Supplementary material associated with this article can be found in the online version.

\section{References}

Andreozzi, R., Caprio, V., Marotta, R., Vogna, D., 2003. Paracetamol oxidation from aqueous solutions by means of ozonation and $\mathrm{H}_{2} \mathrm{O}_{2} / \mathrm{UV}$ system. Water Research 37, 993-1004.

APHA-AWWA-WEF, 1998. Standard methods for the examination of water and wastewater, 20th ed. Washington, DC. personal care products (PPCPs) in surface and treated waters of Louisiana, USA and Ontario, Canada. Sci. Total Environ. 311, 135-149. 
Brillas, E., Sires, I., Arias, C., Cabot, P.L., Centellas, F., Rodriguez, R.M., Garrido, J.A., 2005. Mineralization of paracetamol in aqueous medium by anodic oxidation with a boron-doped diamond electrode. Chemosphere 58, 399-406.

Crane, M., Watts, C., Boucard, T., 2006. Chronic aquatic environmental risks from exposure to human pharmaceuticals. Sci. Total Environ. 367, 23-41.

Fent, K., Weston, A.A., Caminada, D., 2006. Ecotoxicology of human pharmaceuticals. Aquat. Toxicol. 76, 122-159.

Granberg, R.A., Rasmuson, A.C., 1999. Solubility of paracetamol in pure solvents. J. Chem. Eng. Data 44, 1391-1395.

Graham, N., Jiang, C.C., Li, X.Z., Jiang, J.Q., Ma, J., 2004. The influence of pH on the degradation of phenol and chlorophenols by potassium ferrate. Chemosphere $56,949-956$.

Huang, H., Sommerfeld, D., Dunn, B.C., Eyring, E.M., Lloyd, C.R., 2001. Ferrate(VI) oxidation of aqueous phenol: Kinetics and mechanism. J. Phys. Chem. A 105, $3536-3541$.

Jeffrey J. Werner, William A. Arnold, McNeill, K., 2006. Water Hardness as a Photochemical Parameter: Tetracycline Photolysis as a Function of Calcium Concentration, Magnesium Concentration, and $\mathrm{pH}^{+}$. Environ. Sci. Technol. 40, 7236-7241.

Jia, H.D., Yang, X.L., Yang, Y., Gao, Y.F., 1999. Direct spectrophotometric determination of ferrate(VI). Chin. J. Anal. Chem. 27, 617-617.

Jiang, J.Q., Lloyd, B., 2002. Progress in the development and use of ferrate(VI) salt as 
an oxidant and coagulant for water and wastewater treatment. Water Research 36, 1397-1408.

Jiang, J.Q., Wang, S., Panagoulopoulos, A., 2006. The exploration of potassium ferrate(VI) as a disinfectant/coagulant in water and wastewater treatment. Chemosphere 63, 212-219.

Jiang, J.Q., 2007. Research progress in the use of ferrate(VI) for the environmental remediation. J. Hazard. Mater. 146, 617-623.

Jiang, J.Q., Stanford, C., Alsheyab, M., 2009. The online generation and application of ferrate(VI) for sewage treatment-A pilot scale trial. Sep. Purif. Technol. 68, $227-231$

Jiang, J.Q., Zhou, Z.W., Patibandla, S., Shu, X.H., 2013. Pharmaceutical removal from wastewater by ferrate(VI) and preliminary effluent toxicity assessments by the zebrafish embryo model. Microchem J. 110, 239-245.

Jiang, J. Q., 2014. Advances in the development and application of ferrate(VI) for water and wastewater treatment. Journal of Chemical Technology \& Biotechnology $89,165-177$.

Khetan, S.K., Collins, T.J., 2007. Human pharmaceuticals in the aquatic environment: A challenge to green chemistry. Chem. Rev. 107, 2319-2364.

Kasprzyk-Hordern, B., Dinsdale, R.M., Guwy, A.J., 2008. The occurrence of pharmaceuticals, personal care products, endocrine disruptors and illicit drugs in surface water in South Wales, UK. Water Research 42, 3498-3518.

Kim, J.W., Jang, H.S., Kim, J.G., Ishibashi, H., Hirano, M., Nasu, K., Ichikawa, N., 

Personal Care Products (PPCPs) in Surface Water from Mankyung River, South Korea. J. Health Sci. 55, 249-258.

Lee, Y., Cho, M., Kim, J.Y., Yoon, J., 2004. Chemistry of ferrate (Fe(VI)) in aqueous solution and its applications as a green chemical. Journal of Industrial and Engineering Chemistry 10, 161-171.

Li, C., Li, X.Z., Graham, N., 2005. A study of the preparation and reactivity of

Liu, J.L., Wong, M.H., 2013. Pharmaceuticals and personal care products (PPCPs): A review on environmental contamination in China. Environ. Int. 59, 208-224.

Moctezuma, E., Leyva, E., Aguilar, C.A., Luna, R.A., Montalvo, C., 2012. 64, 439-447.

Roberts, P.H., Thomas, K.V., 2006. The occurrence of selected pharmaceuticals in wastewater effluent and surface waters of the lower Tyne catchment. Sci. Total Environ. 356, 143-153. constructed wetlands. Journal of Hydrology 404, 130-135. 
Sharma, V.K., 2002. Potassium ferrate(VI): an environmentally friendly oxidant. Adv. Environ. Res. 6, 143-156.

Sharma, V.K., 2010. Oxidation of inorganic compounds by ferrate(VI) and ferrate(V): one-electron and two-electron transfer steps. Environ. Sci. Technol. 44, 5148-5152.

Sharma,V.K., Zboril, R., Varma, R.S., 2015. Ferrates: greener oxidants with multimodal action in water treatment technologies, Accounts of Chem. Res. 48 182-191.

Santos, A., Yustos, P., Quintanilla, A., Rodríguez, S., García-Ochoa, F., 2002. Route of the catalytic oxidation of phenol in aqueous phase. Applied Catalysis B: Environmental 39, 97-113.

Skoumal, M., Cabot, P.L., Centellas, F., Arias, C., Rodríguez, R.M., Garrido, J.A., Brillas, E., 2006. Mineralization of paracetamol by ozonation catalyzed with $\mathrm{Fe}^{2+}$, $\mathrm{Cu}^{2+}$ and UVA light. Applied Catalysis B: Environmental 66, 228-240.

Tao, H., Liang, X., Zhang, Q., Chang, C.T., 2015. Enhanced photoactivity of graphene/titanium dioxide nanotubes for removal of Acetaminophen. Applied Surface Science 324, 258-264.

Trovo, A.G., Santos Melo, S.A., Pupo Nogueira, R.F., 2008. Photodegradation of the pharmaceuticals amoxicillin, bezafibrate and paracetamol by the photo-Fenton process - Application to sewage treatment plant effluent. Journal of Photochemistry and Photobiology a-Chemistry 198, 215-220.

Wang, H. Y., Liu, Y. B., Zeng, F. C., Song, S., 2015. Electrochemical Synthesis of Ferrate (VI) by Regular Anodic Replacement. Int. J. Electrochem. Sci. 10, 7966- 
500 Wang, J., Fu, W., He, X., Yang, S., Zhu, W., 2014. Catalytic wet air oxidation of

501 phenol with functionalized carbon materials as catalysts: Reaction mechanism and

502 pathway. Journal of Environmental Sciences 26, 1741-1749.

503 Witorsch, R.J., Thomas, J.A., 2010. Personal care products and endocrine disruption:

504 A critical review of the literature. Crit. Rev. Toxicol. 40, 1-30.

505 Yang, L., Yu, L.E., Ray, M.B., 2008. Degradation of paracetamol in aqueous solutions

506 by $\mathrm{TiO} 2$ photocatalysis. Water Research 42, 3480-3488.

507 Yang, L., Yu, L.E., Ray, M.B., 2008. Degradation of paracetamol in aqueous solutions 508 by TiO2 photocatalysis. Water Res. 42, 3480-3488.

509 Yang, B., Ying, G.G., Zhao, J.L., Liu, S., Zhou, L.J., Chen, F., 2012. Removal of 510 selected endocrine disrupting chemicals (EDCs) and pharmaceuticals and personal 511 care products (PPCPs) during ferrate(VI) treatment of secondary wastewater 512 effluents. Water Research 46, 2194-2204.

513 Zhou, Z., Jiang, J. Q., 2015. Reaction kinetics and oxidation products formation in the 514 degradation of ciprofloxacin and ibuprofen by ferrate(VI). Chemosphere 119, $515 \quad$ Supplement, S95-S100. 
517 Fig. 1. Effect of reaction time and ferrate (VI) dosage on AAP degradation

518 Fig. 2. Effect of different $\mathrm{pH}$ values on AAP degradation

519 Fig. 3. Kinetics analysis of AAP degradation by ferrate (VI)

520 Fig. 4. Detection of oxidation products $(a-c)$ and original compound, AAP (d)

521 Fig. 5. Evolution of OPs and nitrate with decreasing of AAP concentration

522 Fig. 6. Possible pathways of AAP degradation by ferrate (VI)

523 Fig. 7. Effect of different HA dosage on AAP degradation

524 Fig. 8. Effect of different ions on AAP degradation 


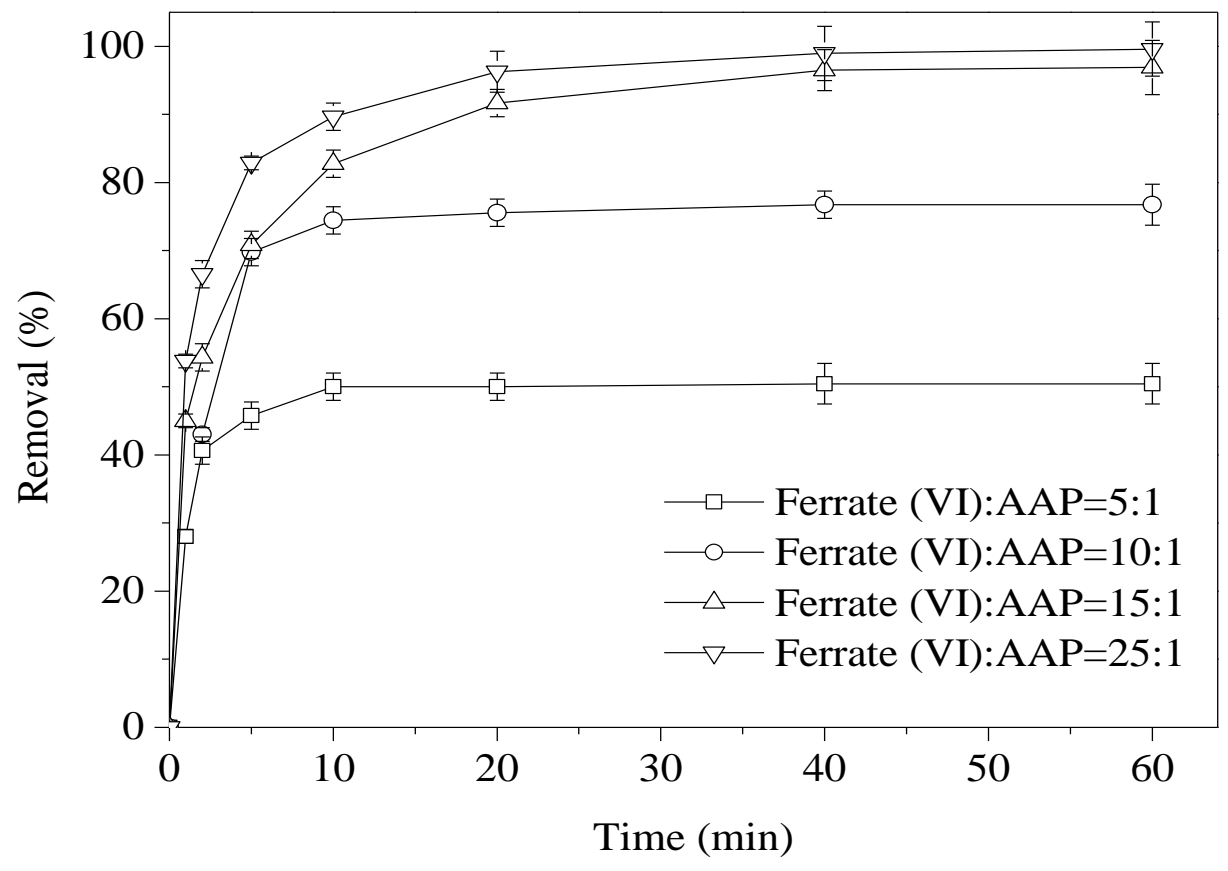

526

Fig. 1. Effect of reaction time and ferrate (VI) dosage on AAP degradation 


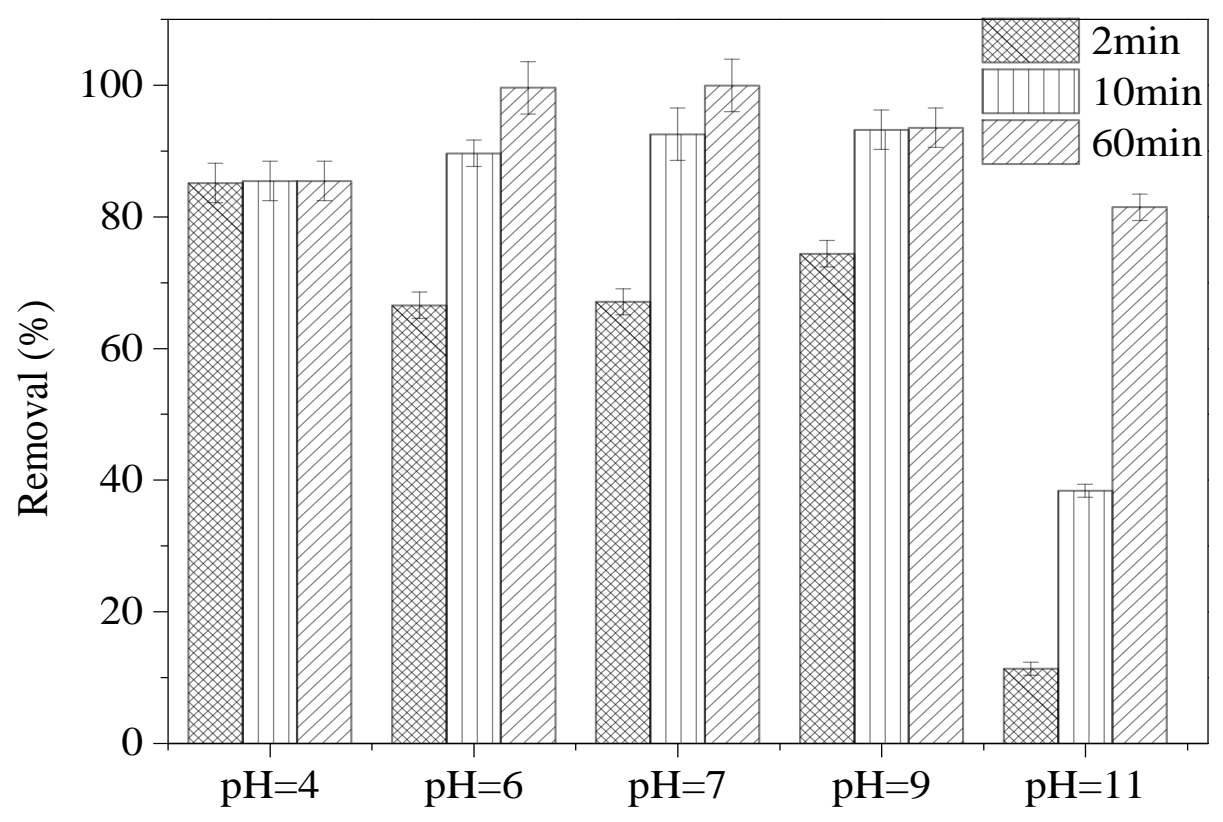

529 Fig. 2. Effect of different $\mathrm{pH}$ values on AAP degradation 


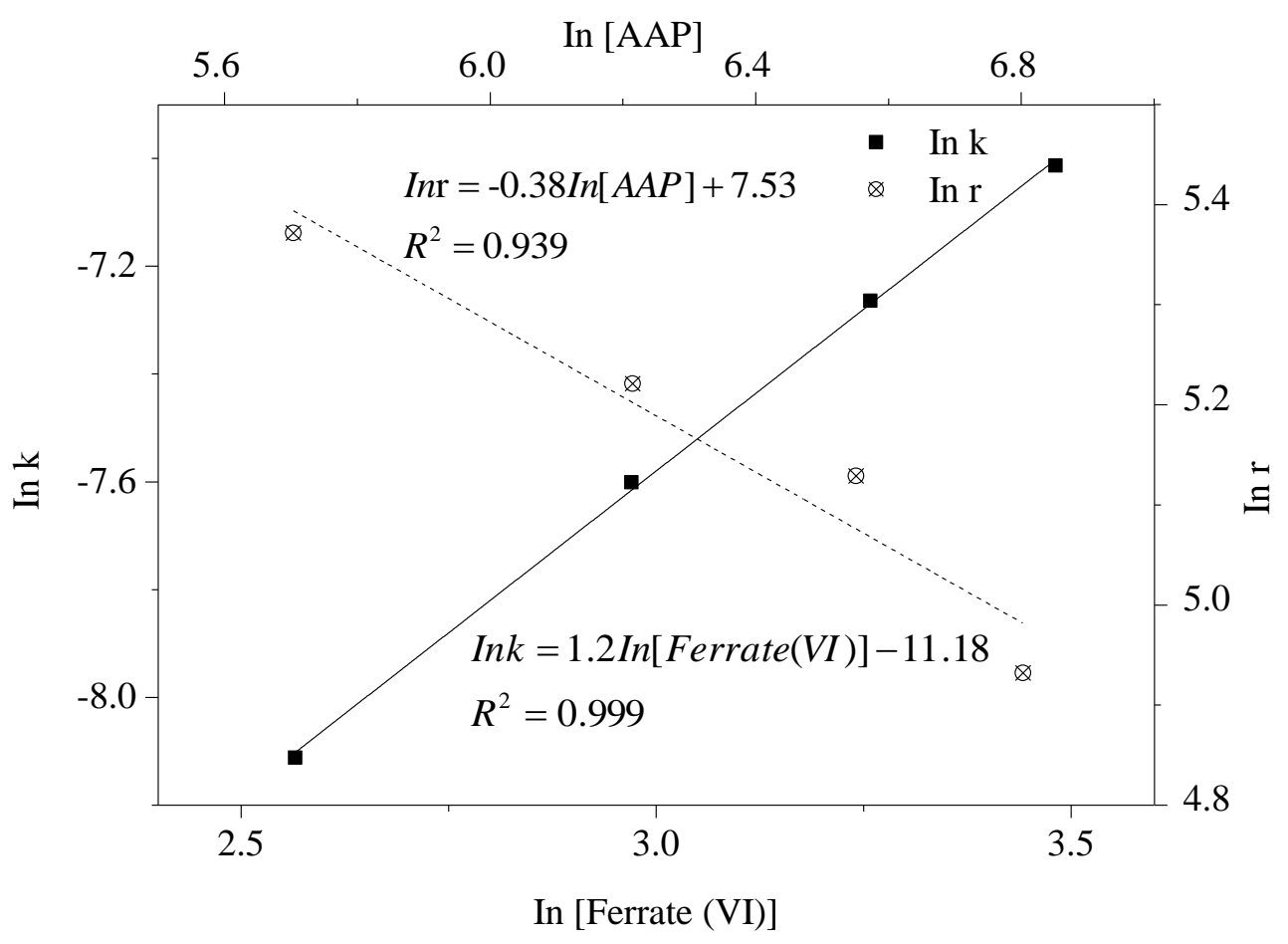

531

532 Fig. 3. Kinetics analysis of AAP degradation by ferrate (VI)

533 

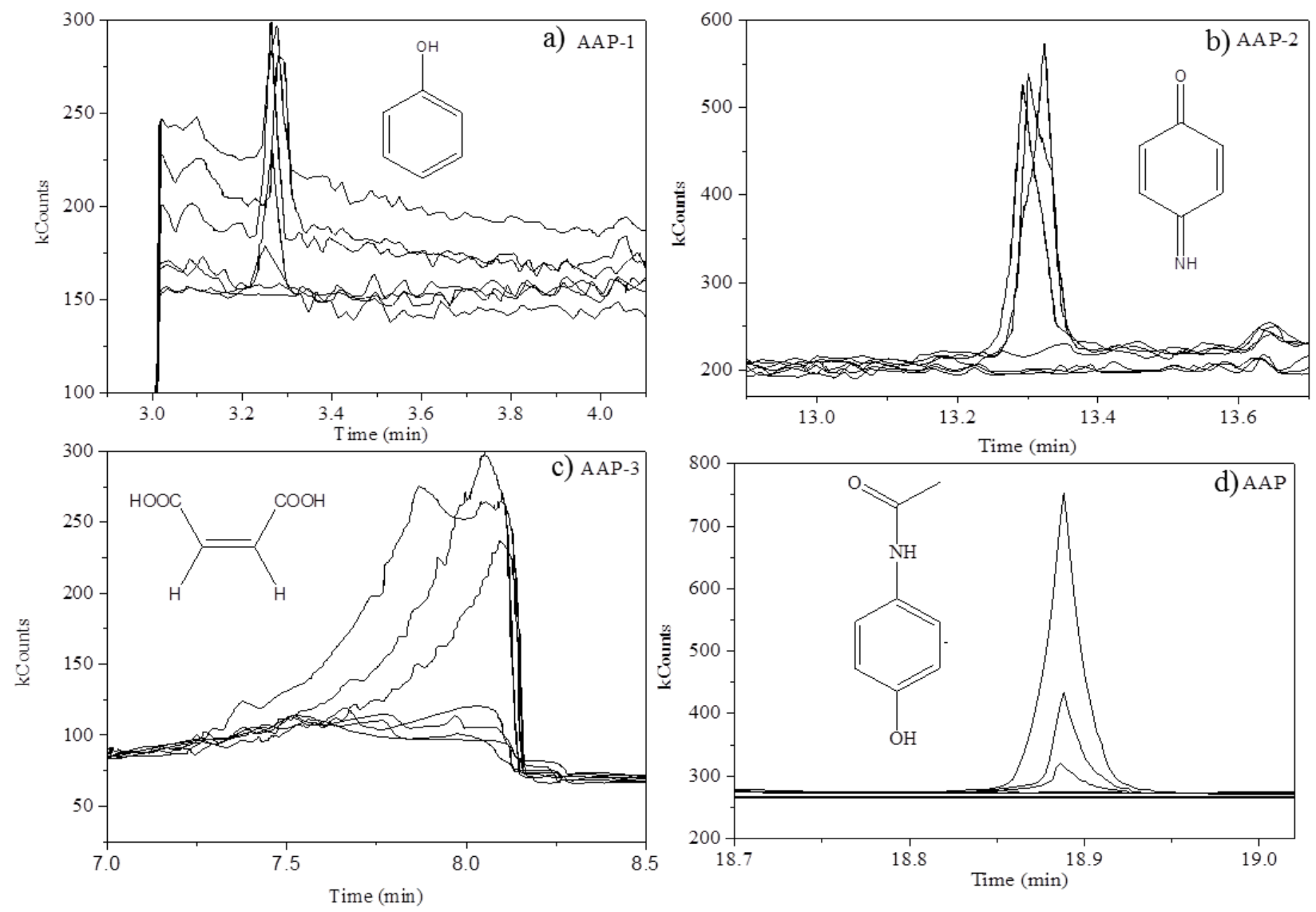

534

Fig. 4. Detection of oxidation products $(\mathrm{a}-\mathrm{c})$ and original compound, AAP $(\mathrm{d})$ 


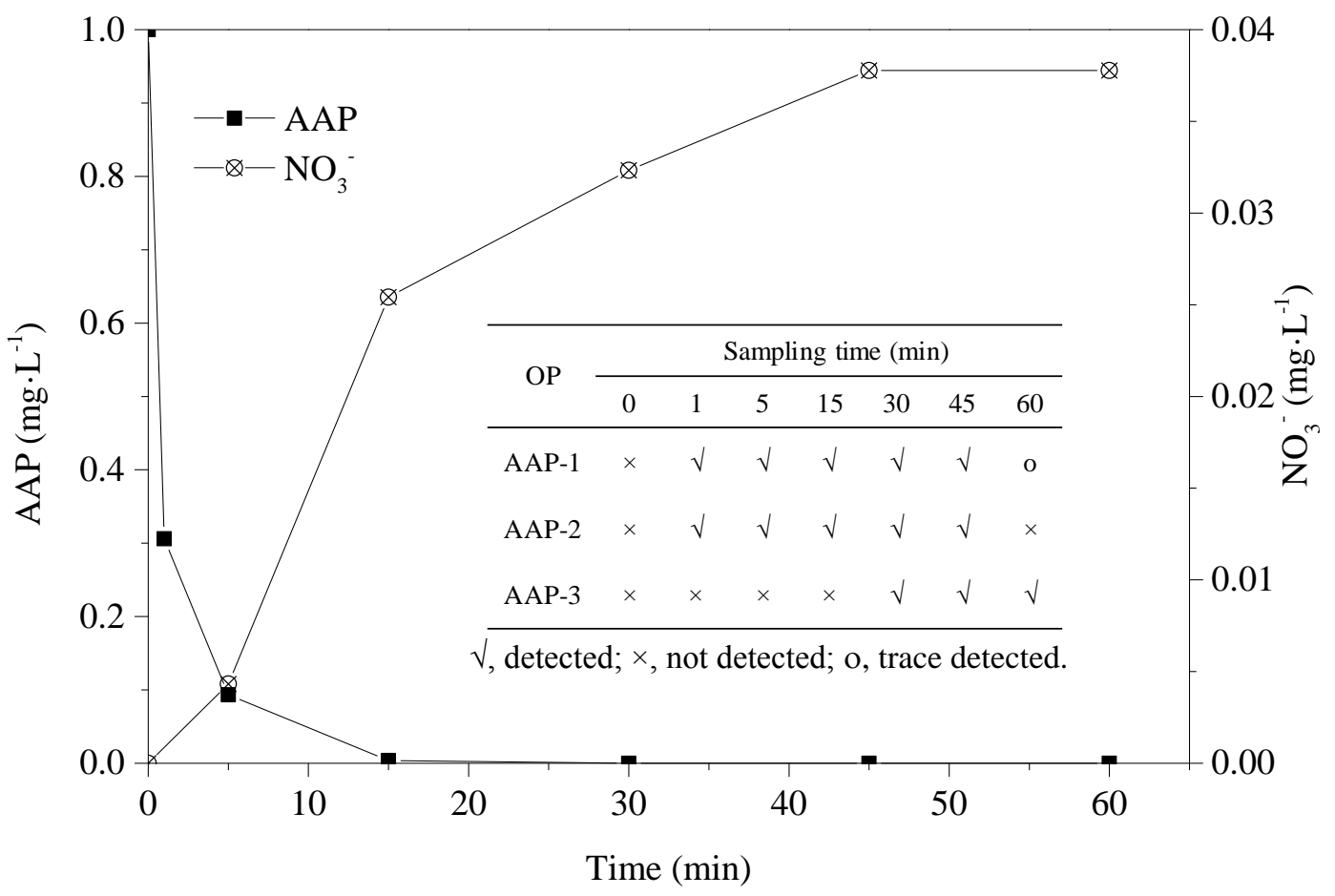

537

Fig. 5. Evolution of OPs and nitrate with decreasing of AAP concentration 


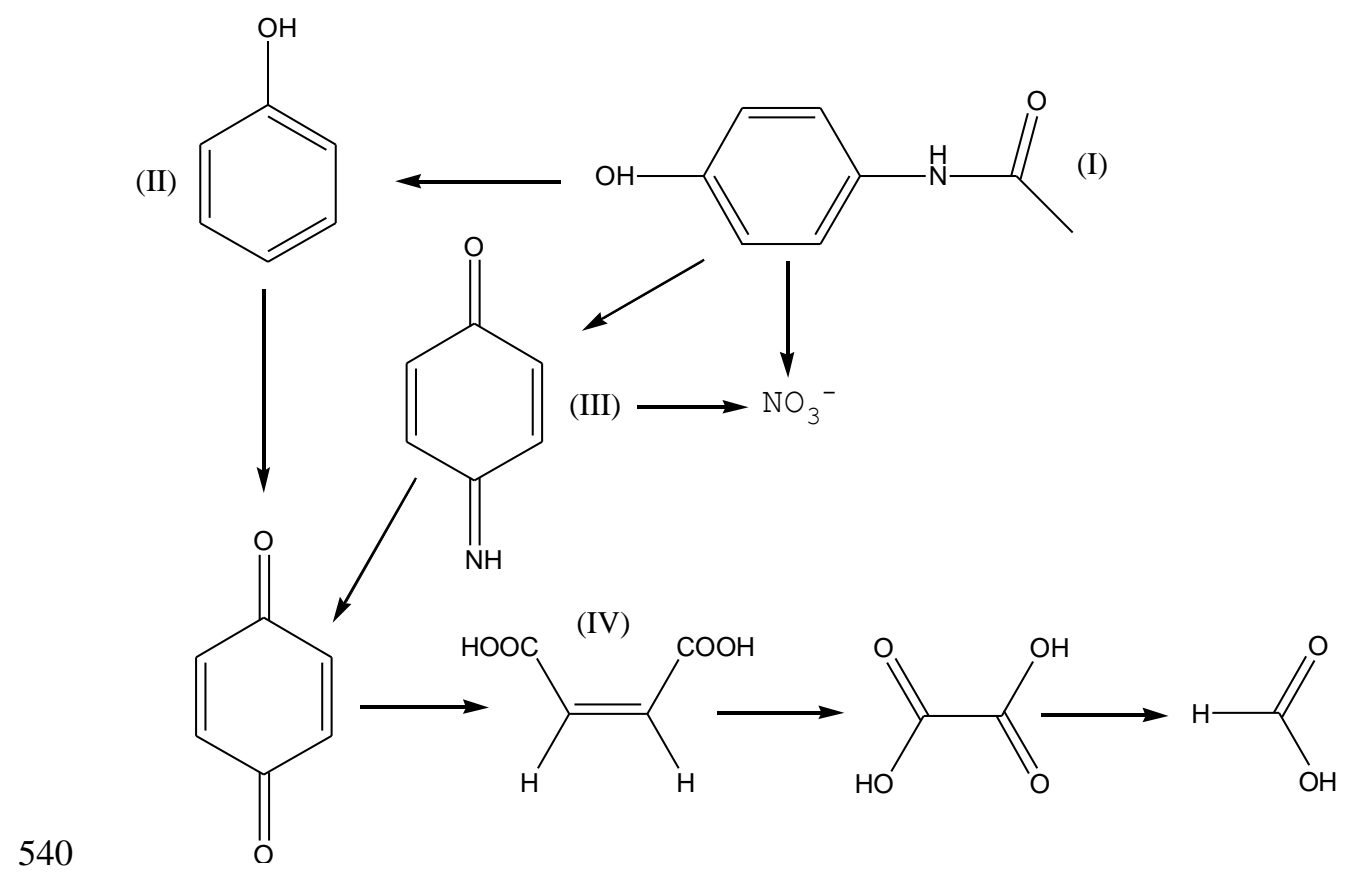

541 Fig. 6. Possible pathways of AAP degradation by ferrate (VI) 


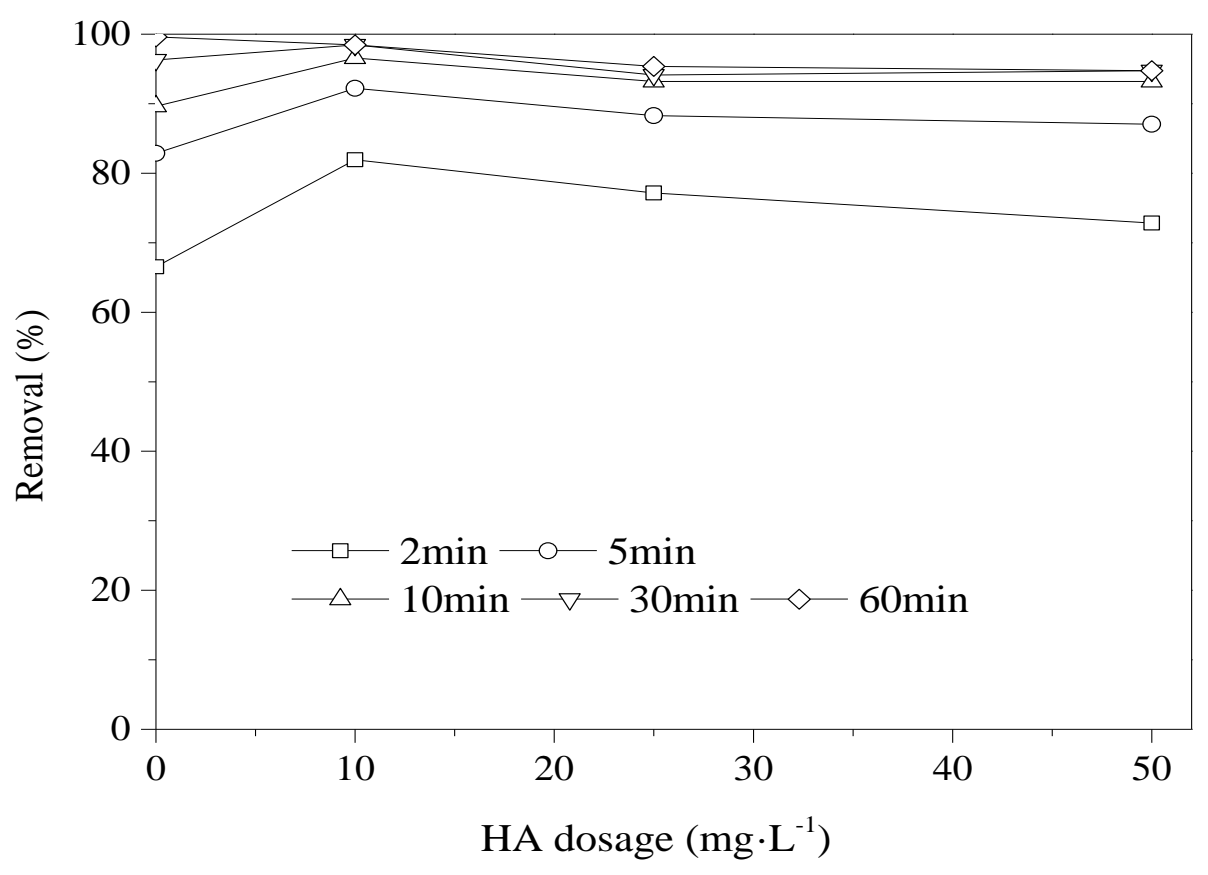

542

543 Fig. 7. Effect of different HA dosage on AAP degradation 

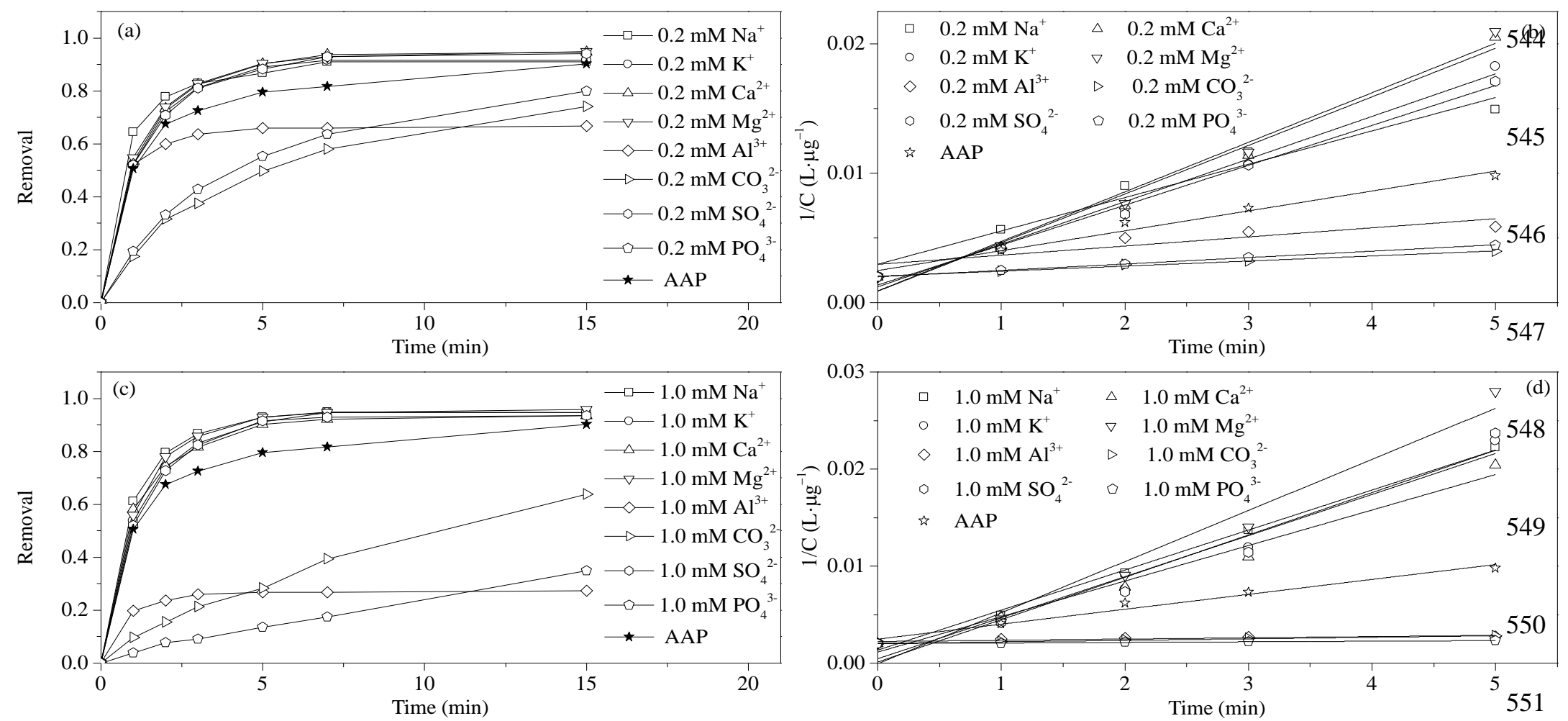

Fig. 8. Effect
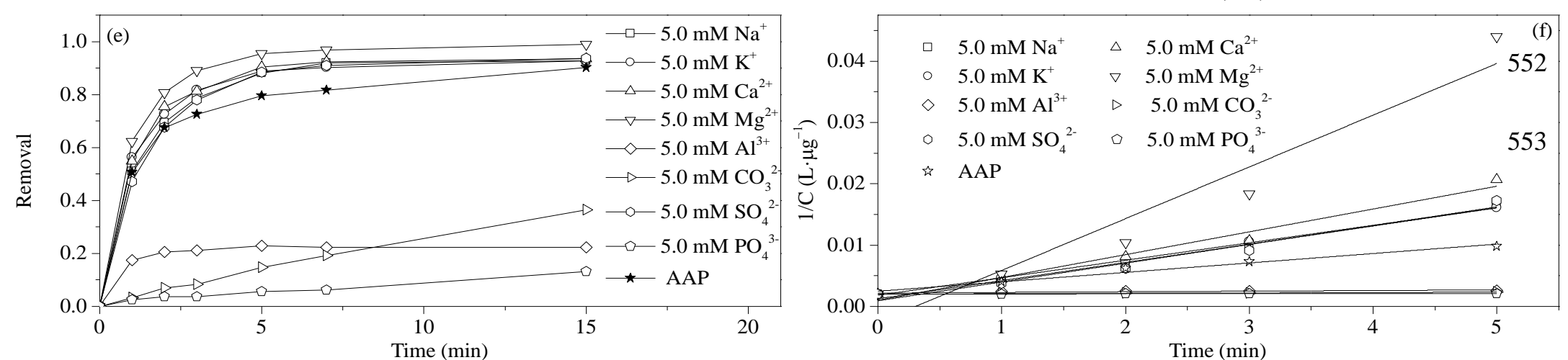

of different

ions on AAP

degradation 
555 Kinetic parameters of AAP degradation by ferrate (VI)

\begin{tabular}{cccccc}
\hline $\begin{array}{c}\mathrm{D}_{\text {Ferate }(\mathrm{VI})} \\
\left(\mathrm{mg} \cdot \mathrm{L}^{-1}\right)\end{array}$ & $\begin{array}{c}\mathrm{C}_{\mathrm{IAAP}} \\
\left(\mu \mathrm{g} \cdot \mathrm{L}^{-1}\right)\end{array}$ & Fitting equation & $\mathrm{K}_{\mathrm{obs}}\left(\mathrm{min}^{-1}\right)$ & $\mathrm{R}^{2}$ & $\begin{array}{c}\mathrm{R}_{\mathrm{IR}} \\
\left(\mu \mathrm{g} \cdot \mathrm{L}^{-1} \cdot \mathrm{min}^{-1}\right)\end{array}$ \\
\hline 13 & 1000 & $1 / \mathrm{C}=0.0003 \mathrm{X}+0.0012$ & 0.0003 & 0.9093 & 208.3 \\
19.5 & 1000 & $1 / \mathrm{C}=0.0005 \mathrm{X}+0.0012$ & 0.0005 & 0.9946 & 347.2 \\
26 & 1000 & $1 / \mathrm{C}=0.0007 \mathrm{X}+0.0013$ & 0.0007 & 0.9943 & 414.2 \\
32.5 & 1000 & $1 / \mathrm{C}=0.0009 \mathrm{X}+0.0012$ & 0.0009 & 0.9961 & 625.0 \\
32.5 & 900 & $\ln \mathrm{C}=-0.2647 \mathrm{X}+6.2611$ & 0.2647 & 0.9088 & 138.6 \\
32.5 & 700 & $\ln \mathrm{C}=-0.3920 \mathrm{X}+6.0656$ & 0.3920 & 0.9596 & 168.9 \\
32.5 & 500 & $\ln \mathrm{C}=-0.5504 \mathrm{X}+5.8182$ & 0.5504 & 0.9694 & 185.1 \\
32.5 & 300 & $\ln \mathrm{C}=-0.8308 \mathrm{X}+5.5569$ & 0.8308 & 0.9665 & 215.2 \\
\hline
\end{tabular}

$556 \quad \mathrm{D}_{\text {Ferate (VI) }}$ :Ferate (VI) dosage

$557 \quad \mathrm{C}_{\text {IAAP }}$ :Initial concentration of AAP

$558 \quad \mathrm{~K}_{\mathrm{obs}}$ :The pseudo reaction rate constant

$559 \mathrm{R}_{\mathrm{IR}}:$ Initial reaction rate 
561 Kinetic parameters of the AAP degradation in the presence of 8 dissolved ions

\begin{tabular}{|c|c|c|c|c|c|c|c|c|c|}
\hline Parameter & $\begin{array}{c}D_{\text {ions }} \\
(\mathrm{mM})\end{array}$ & $\mathrm{Na}^{+}$ & $\mathrm{K}^{+}$ & $\mathrm{Ca}^{2+}$ & $\mathrm{Mg}^{2+}$ & $\mathrm{Al}^{3+}$ & $\mathrm{CO}_{3}{ }^{2-}$ & $\mathrm{SO}_{4}^{2-}$ & $\mathrm{PO}_{4}^{3-}$ \\
\hline $\begin{array}{c}\mathrm{K}_{\mathrm{obs}}\left(\mathrm{min}^{-}\right. \\
\left.{ }^{-}\right)\end{array}$ & \multirow{2}{*}{0.2} & 0.0026 & 0.0033 & 0.0038 & 0.0038 & 0.0007 & 0.0004 & 0.0031 & 0.0005 \\
\hline $\mathrm{R}^{2}$ & & 0.9661 & 0.9905 & 0.9837 & 0.9842 & 0.7765 & 0.9944 & 0.9925 & 0.9999 \\
\hline $\begin{array}{c}\mathrm{K}_{\mathrm{obs}}\left(\mathrm{min}^{-}\right. \\
\left.{ }^{-}\right)\end{array}$ & \multirow{2}{*}{1} & 0.0041 & 0.0042 & 0.0037 & 0.0053 & 0.0001 & 0.0002 & 0.0044 & $6.1 \times 10^{-5}$ \\
\hline $\mathrm{R}^{2}$ & & 0.9963 & 0.9729 & 0.9829 & 0.9700 & 0.6713 & 0.9893 & 0.9583 & 0.9789 \\
\hline $\begin{array}{c}\mathrm{K}_{\mathrm{obs}}\left(\mathrm{min}^{-}\right. \\
{ }^{-}\end{array}$ & \multirow[t]{2}{*}{5} & 0.0030 & 0.0029 & 0.0037 & 0.0084 & 0.0001 & $6.8 \times 10^{-5}$ & 0.0031 & $2.2 \times 10^{-5}$ \\
\hline $\mathrm{R}^{2}$ & & 0.9852 & 0.9989 & 0.9787 & 0.9340 & 0.6352 & 0.9887 & 0.9728 & 0.9012 \\
\hline
\end{tabular}

$\mathrm{D}_{\text {ion }}$ :The ions dose

$563 \mathrm{~K}_{\mathrm{obs}}$ :The pseudo reaction rate constant 
Table 3

Effect of aluminum ions on ferrate (VI) concentration

\begin{tabular}{cccccccc}
\hline $\begin{array}{c}\mathrm{V}_{\text {aluminum }} \\
(\mu \mathrm{L})\end{array}$ & 0 & 10 & 100 & 200 & 300 & 400 & 500 \\
\hline $\begin{array}{c}\mathrm{C}_{\text {Ferrate }(\mathrm{VI})} \\
(\mathrm{mM})\end{array}$ & 13.2 & 12.8 & 11.5 & 8.9 & 6.6 & 4.3 & 2.8 \\
\hline & \\
$\mathrm{V}_{\text {aluminum }}:$ The volume of aluminum ions \\
$\mathrm{C}_{\text {Ferrate (VI): }}$ The concentration of ferrate (VI)
\end{tabular}

